\title{
Política externa do Brasil desde a redemocratização: evolução, mudanças e perspectivas futuras. ${ }^{1}$
}

Eiiti Sato ${ }^{2}$

Professor de Relações Internacionais

Universidade de Brasília - UnB

irel.sato@gmail.com

Como citar este artigo: SATO, E.. "Política externa do Brasil desde a redemocratização: evolução, mudanças e perspectivas futuras", Intelligere, Revista de História Intelectual, nº10, pp. 70-90. 2020. Disponível em $<$ http://revistas.usp.br/revistaintelligere $>$. Acesso em dd/mm/aaaa:

Resumo: Este ensaio tem por objetivo apresentar uma reflexão sobre as perspectivas do Brasil no cenário internacional. O ensaio faz um balanço resumido da política externa brasileira após os governos militares revelando que os sucessivos governos eleitos pelo voto desde 1989 procuraram estabelecer prioridades e objetivos na política externa presumivelmente baseados na busca por uma coerência entre as demandas internas e as mudanças em curso no cenário internacional. Apesar de tudo, o pouco dinamismo na ordem interna e a ausência de uma visão mais orgânica e estruturada da nação no cenário internacional têm comprometido $\mathrm{O}$ desempenho do país tanto em termos econômicos quanto político. A conclusão é que os dados mostram que a estagnação tem sido a nota marcante da relevância do Brasil no cenário internacional tanto em termos regionais quanto globais. O ensaio é dedicado a Amado Luiz Cervo, notável professor de política externa brasileira na Universidade de Brasília, que agora completa oito décadas de uma vida produtiva e inspiradora.

\footnotetext{
${ }^{1}$ Este ensaio foi escrito em homenagem ao notável historiador Amado Luiz Cervo, Professor Emérito da Universidade de Brasília que completa 80 anos de uma vida extremamente produtiva. Formou toda uma geração de estudiosos e suas obras tornaram-se referência para todos aqueles que se interessam por relações internacionais e, mais especificamente, pela trajetória do Brasil no cenário internacional.

${ }^{2}$ EIITI SATO é professor do Instituto de Relações Internacionais da Universidade de Brasília (IREL/UnB). Foi Diretor do IREL/UnB de 2006 a 2014. Foi Chefe da Assessoria Internacional da UnB (2014-2016). Foi o primeiro Presidente da Associação Brasileira de Relações Internacionais - ABRI (2005-2007). Tem ministrado regularmente cursos sobre Economia Política Internacional e Política Internacional, Teoria e História. Ref.: irel.sato@gmail.com http://lattes.cnpq.br/8614060463115652).
} 
Palavras-chave: Política externa brasileira; redemocratização no Brasil; multilateralismo e regionalismo.

Brazilian foreign policy since re-democratization: main developments, changes and perspectives for the near future

Abstract: The purpose of this essay is to present some remarks, which seem relevant to capture some current perspectives to Brazil in the world scene. The essay starts with a brief account of the Brazilian foreign policy along the period since the militaries have left power in Brazil. The account reveals that the successive presidents elected democratically since 1989 have developed foreign policy trying to match domestic demands and international trends. Nevertheless, figures show that in general terms the achievements were rather poor due to the fact that there was not enough dynamism in the domestic business environment which combined with a short sighted view on world affairs. The essay concludes that unfortunately an overall balance shows that Brazil has remained stagnated in political and economic terms along the last quarter in both global and regional levels. The essay pays tribute to Amado Luiz Cervo who is an outstanding professor of Brazilian foreign policy at the University of Brasilia who is now completing four scores of a very productive and inspiring life.

Keywords: Brazilian foreign policy; re-democratization in Brazil; multilateralism and regionalism.

Nas relações exteriores, o fim dos governos militares marcou também o fim do projeto "Brasil Potência". Os equívocos e, por fim, o fracasso na administração da crise do petróleo levaram o país a um pesado endividamento que se revelaria um fardo cujo peso seria decisivo para impedir qualquer possibilidade de dar continuidade a um projeto como o "Brasil Potência", que demandaria taxas de crescimento econômico consistentes e mais elevadas do que a média mundial, além de investimentos pesados em infraestrutura econômica e estratégica para servir de base para um longo período de crescimento consistente. Em outras palavras, a manutenção de um tal projeto exigiria capacidade para atuar em consonância com as lideranças inovadoras em escala mundial, além de condições econômicas para participar com desenvoltura dos mercados comerciais e financeiros, que se ampliavam e se tornavam cada vez mais competitivos, o que seria impossível com uma economia debilitada como era o caso do Brasil do início da década de 1980. 
O fim dos governos militares também coincidiu com mudanças substanciais no cenário internacional, onde a guerra fria perdia seu papel e a crise do petróleo mudava de forma bastante radical as condições econômicas internacionais, inviabilizando a continuidade das políticas que o país vinha praticando inclusive na esfera das relações exteriores. Em consequência, após a década de 1980, os governos não tinham outra opção a não ser buscar novos caminhos para a inserção do Brasil no cenário internacional. O caminho escolhido foi o de passar a olhar mais para a vizinhança e para as economias em desenvolvimento e menos para as grandes potências. Nesse quadro, algumas opções encontradas foram investir na integração regional e no multilateralismo e, de uma forma geral, procurar construir novas alianças, em especial com os países em desenvolvimento. O problema é que nessa busca, os sucessivos governos, preocupados com a retomada da democracia entendida apenas como voto e representação, não conseguiram imprimir o necessário dinamismo e a integração das forças econômicas e políticas da nação. $\mathrm{O}$ resultado tem sido o baixo desempenho da economia e a consequente estagnação da posição brasileira no cenário internacional.

Assim, neste breve ensaio, esse processo de mudança será analisado resumidamente para construir algumas especulações sobre as perspectivas do Brasil no futuro próximo, no âmbito das relações internacionais neste primeiro quarto do século XXI já notavelmente marcado por turbulências, transformações e por muitas incertezas.

\section{Uma visão renovada da integração regional}

A orientação da política exterior do Brasil no sentido da formação de um sistema regional viveu seu momento de maior interesse na década de 1990. Após a transformação da AlALC em ALADI pelo Tratado de Montevideo em 1980, entre outras disposições, incorporou uma cláusula semelhante à cláusula XXIV do GATT, permitindo que as diferenças sub-regionais fossem levadas em conta em projetos de integração na América Latina. Tratava-se de uma disposição importante pois, como argumentavam analistas e observadores

como Hélio Jaguaribe, uma das grandes dificuldades de um processo de integração na América Latina formando um só bloco, como se pretendia com a AlALC, eram as enormes disparidades econômicas, culturais e sociais, 
formando um "aglomerado excessivamente heterogêneo e desequilibrado de países", e fazendo com que uma integração horizontal de toda a região fosse completamente inviável (JAGUARIBE, 1992, p.31). Nesse sentido, um arranjo sub-regional como o Mercosul, ao reunir apenas quatro países vizinhos no sul do continente apresentava chances bem maiores de constituir um arranjo regional de sucesso. ${ }^{3}$ Por meio do Mercosul, Argentina, Brasil, Paraguai e Uruguai podiam fazer avançar um sistema regional sem precisar preocupar-se em acomodar problemas e demandas de nações tão distantes e díspares como Guatemala, Equador ou México. Vale notar também que o fim do ciclo dos governos militares na região fazia com que os governos eleitos se aproximassem mais do mercado e de sua mecânica tornando esses governos mais previsíveis, especialmente no que tange a políticas de estabilização econômica.

Uma característica da época era o entendimento de que o mundo vivia a era dos blocos econômicos. O sucesso da Comunidade Econômica Europeia (CEE), que acabava de evoluir para uma união econômica, completando assim, o ciclo da integração econômica previsto na teoria, exercia grande influência sobre o ambiente político e intelectual especialmente na América Latina. Entre outros fenômenos notáveis da época, o fim da guerra fria trouxe como um dos efeitos mais imediatos a corrida frenética dos países que integravam o bloco soviético no sentido de se tornarem membros da União Europeia. Em outras palavras, em muitos sentidos, essa corrida para a União Europeia confirmava com fatos a hipótese extremamente atraente de que a formação de blocos era não apenas um arranjo comercial que podia promover o desenvolvimento econômico, mas também um arranjo político capaz de promover a paz, como haviam argumentado os "pais fundadores" da integração europeia como Maurice Schumann, Konrad Adenauer, Paul-Henri Spaak, Jean Monnet e todos os líderes que, no pós-guerra imediato, faziam parte das várias associações voltadas para a promoção da unidade da Europa em torno de um grande projeto comum. Nesse quadro, a formação de blocos emergia como

\footnotetext{
${ }^{3}$ Mesmo antes da transformação da ALALC em ALADI, já existiam iniciativas de integração sub-regional como o Sistema de Integração Centro-Americana (SICA), de 1951, e o Pacto Andino ou Grupo Andino criado em 1969, reforçando a importância de facilitar a formação de arranjos sub-regionais.
} 
alternativa para as nações em toda parte e não apenas para o Brasil, que buscava uma alternativa para sua política exterior.

De fato, o interesse pela integração regional motivava até mesmo uma nação poderosa como os EUA - à época considerada a única superpotência após o colapso da União Soviética. Com efeito, o governo dos EUA concebeu a Área de Livre Comércio das Américas (ALCA), que deveria englobar os países das três Américas. ${ }^{4}$ Houve muitas resistências, inclusive dentro dos EUA, e a proposta não prosperou. Em seu lugar, sob a liderança dos EUA foi criado em Janeiro de 1994 o NAFTA (North American Free Trade Agreement) como bloco sub-regional reunindo EUA, Canadá e México. Foi nesse ambiente que surgiu o Mercosul (Mercado Comum do Sul), estabelecido pelo Tratado de Assunção assinado em Março de 1991, formando uma união aduaneira que, mais tarde, poderia evoluir para formas mais completas de integração econômica.

$\mathrm{Na}$ realidade, no Brasil, o interesse pela integração regional, assim como as bases para a formação do Mercosul emergiram ainda na década de 1980, em grande medida como resultado de mudanças no ambiente político e econômico ocorridas na região. Com efeito, do ponto de vista econômico, a década de 1980 ficou conhecida como a década perdida para boa parte dos países da América Latina, que saíram da crise do petróleo endividados e impossibilitados de continuar com as estratégias de desenvolvimento que haviam permitido elevadas taxas de crescimento na década de 1960 e início dos anos 1970 (PeArson Commission, 1969). ${ }^{5}$ As duas nações de maior peso econômico e político na região - Argentina e Brasil - viviam as frustrações e o declínio dos governos militares, que deixavam o poder melancolicamente. $\mathrm{Na}$ Argentina a nação ainda cuidava das feridas físicas e morais da derrota dos governos militares na Guerra das Malvinas enquanto, no Brasil, o sonho de um "Brasil Potência" havia se desfeito num pesado endividamento que deixava

\footnotetext{
4 A Área de Livre Comércio das Américas (ALCA) foi uma iniciativa dos EUA proposta formalmente durante a Cúpula das Américas, realizada em Miami, no dia 9 de dezembro de 1994. Nesse arranjo seriam eliminadas as barreiras alfandegárias entre os 34 países americanos, com exceção de Cuba.

${ }^{5}$ Ver o relatório da PEARSON COMMISSION, que proporciona uma visão panorâmica do desempenho econômico da economia mundial na década de 1960. No Brasil o período compreendido entre 1967 e 1973 ficou conhecido como os anos do "milagre brasileiro" devido às elevadas taxas de crescimento superiores a $10 \%$ ao ano.
} 
exposta a incômoda e impopular dependência externa e cujos efeitos para a sociedade se traduziam em aumento da pobreza e da inflação. Em 1982 realizou-se uma grande operação diplomática e financeira para evitar o default, mas cinco anos depois, o governo brasileiro declarou uma moratória unilateral para evitar o esgotamento das reservas internacionais e forçar uma renegociação das dívidas com credores externos.

Tanto na Argentina quanto no Brasil, que passavam a ser comandados por governos civis, foram deixados de lado os sonhos de projeção de poder internacional e passou-se a buscar alternativas para suprir as necessidades de suas economias e de suas sociedades. Em 1985 os presidentes Alfonsin e Sarney assinaram a Declaração de Iguaçu com o propósito de aprofundar as relações econômicas e comerciais entre os dois países. Além disso, esses presidentes fizeram avançar as negociações que culminariam com o acordo de cooperação nuclear entre Argentina e Brasil criando, em 1991, a Agência Brasileiro-Argentina de Contabilidade e Controle de Materiais Nucleares. $\mathrm{Na}$ realidade, ainda sob os governos militares, em 1979, houve a assinatura do Tratado Tripartite (Argentina, Brasil e Paraguai) sobre o aproveitamento dos recursos energéticos das usinas de Corpus e de Itaipu, dando sinais de que a cooperação regional não era apenas viável e nem uma opção ideológica, mas uma necessidade para a região. Desse modo, a assinatura do Tratado de Assunção que estabelecia em seu Artigo 1 que "Os Estados Partes decidem constituir um Mercado Comum, que deverá estar estabelecido a 31 de dezembro de 1994, e que se denominará "Mercado Comum do Sul (MERCosul)" foi um passo natural no processo de integração real que avançava na região. ${ }^{6}$

Em fins da década de 1990, o MERCosul atingiu seu auge no que tange à sua importância para o comércio exterior de seus integrantes. Apesar de tudo, essa evolução jamais representou sucesso semelhante ao da integração europeia. Enquanto na Europa o comércio intra-bloco sempre fora de grande importância para todos os integrantes do sistema europeu, na América Latina, o comércio dentro da região sempre fora secundário para a maioria dos países.

\footnotetext{
${ }^{6}$ A integração real é feita de formas de interação como o aumento do fluxo internacional de pessoas ou a construção de uma obra como a usina de Itaipu que afeta os interesses de mais de um país normalmente leva a acordos e tratados. Em larga medida, pode-se dizer que a formação da CEE em 1957 foi um arranjo necessário para organizar uma Europa onde a integração real já existia desde a Idade Média.
} 
Em 1990, as exportações brasileiras para os países do Mercosul representavam apenas 4,2\% do total exportado e em 1998 esse percentual havia evoluído para 17,37\%, e o mesmo aconteceu com a Argentina que passou de 14,84\% em 1990 para 35,64\% em 1998. Também cabe notar que, nessas cifras, inclui-se o fato de que a maior parte dos produtos comercializados eram de manufaturados enquanto as exportações tanto do Brasil quanto da Argentina para outros países de fora do bloco eram de produtos primários. Por outro lado, na Europa, o comércio intra-bloco historicamente tem representado, na média, sempre mais de $50 \%$ do comércio exterior de seus integrantes.

Desde os fins da década de 1990 a importância do MERCosul passou a declinar diante da evolução do quadro internacional. No caso do Brasil, o destino das exportações brasileiras para o MERCosul caíra pela metade entre 1998 e 2004, enquanto no caso da Argentina esse percentual se reduzira de 35,64\% em 1998 para 18,59\% em 2004. Essa tendência, em alguma medida, foi resultado também de mudanças que ocorriam no cenário mais geral do comércio internacional, mas foi também influenciado por mudanças na orientação da política externa tanto brasileira quanto argentina, que passaram a enfatizar o lado mais ideológico das relações externas que resultaria na criação em 2008 da UnASUl (União de Nações Sul-Americanas) e no interesse crescente por novas alternativas que emergiam no cenário internacional como o G-20 e o BRICS. Com efeito, no caso do Brasil, a política exterior do governo Lula passou a concentrar suas atenções no multilateralismo, que era o lado mais pragmático da política exterior, e no globalismo, que consistia exatamente no lado mais ideológico, ao entender que o país deveria participar como ator ativo de um presumido grande jogo de poder no cenário mundial.

\section{O multilateralismo e o globalismo}

Multilateralismo é uma expressão que, em sentido genérico, se refere a iniciativas nas quais vários países trabalham de forma cooperativa sobre um ou mais assuntos. Tecnicamente, significa que vários países procuram construir regimes internacionais de forma institucionalmente organizada. Em larga medida, o termo se confunde com organizações internacionais e, por essa razão, quando se fala em multilateralismo é difícil não associar o termo 
organizações como a OMC, em assuntos de comércio, ou a ONU para as questões de segurança internacional. Assim, embora o multilateralismo na política internacional seja antigo, foi transformado em experiência prática na política entre as nações apenas há cerca de um século com o surgimento da Liga das Nações. Assim, o Brasil tem uma tradição de atuação em instâncias multilaterais desde a primeira hora uma vez que sua participação na Liga das Nações foi bastante expressiva e, assim, trata-se de um fato dizer que desde o surgimento da prática do multilateralismo, a diplomacia brasileira sempre atuou nessas instâncias. ${ }^{7}$ Também na criação e consolidação do Sistema Nações Unidas a participação da diplomacia brasileira foi expressiva, inclusive na composição de órgãos e de comissões criadas logo após a criação da ONU.

Dessa forma, no início do século XXI, parece até natural o reavivamento do interesse da diplomacia brasileira pelo multilateralismo. Nas duas administrações do Governo Lula, esse movimento foi caracterizado pelos historiadores Amado Cervo e Clodoaldo Bueno como multilateralismo de reciprocidade e tinha por pano de fundo a orientação geral do Brasil no sentido de integrar-se a um mundo onde a globalização comercial e financeira se tornara uma realidade após o fim da polarização imposta pela guerra fria que condicionava a ação dos países no cenário internacional (CERVO \& BUENO, 2011, p 530-544). Entre as iniciativas do período estava a expansão da rede de representações diplomáticas especialmente no Caribe e no continente africano. A abertura de representação diplomática em países de pouca expressão internacional era uma forma de obter apoio desses países em foros internacionais, isto é, à pratica do multilateralismo (OLIVEIRA; DUCHIADE , 2019). ${ }^{8}$

$\mathrm{Na}$ aposta no multilateralismo durante os dois mandatos do presidente Lula ganhou destaque a demanda por um assento permanente no Conselho de Segurança das Nações Unidas. Os argumentos eram variados, mas se

\footnotetext{
${ }^{7}$ Há várias obras e artigos que discutem essa participação, entre essas obras o livro O Brasil na Liga das Nações. 1919-1926, de autoria de EUGÊNIO VARGAS (Editora Funag/Editora UFRGS, 2000) faz um balanço dessa atuação brasileira.

${ }^{8}$ Em 2019, o Brasil tinha 223 representações no exterior, entre embaixadas, consulados e missões em organizações internacionais. Destas, 72 (32,3\%) foram criadas por Lula e Dilma, incluindo-se um escritório de representação em Ramallah (sede de Autoridade Nacional Palestina) e cinco missões e delegações em organizações internacionais como a AIEA (Agência Internacional de Energia Atômica) e a CPLP (Comunidade dos Países de Língua Portuguesa).
} 
concentravam em algumas hipóteses ou pressupostos que acabaram por se revelar pouco eficazes em termos de resultados esperados. A primeira era a de que a estrutura do processo decisório da ONU havia sido concebida quando a Segunda Guerra Mundial chegava ao fim. Meio século mais tarde, o cenário havia mudado substancialmente, dizia o argumento. Entre essas mudanças, a supremacia americana, embora ainda permanecesse, o diferencial de poder em relação a outras grandes potências havia se reduzido de maneira substancial (KENNEDy, 1988, p. 475). . Além do mais Japão, Alemanha e Itália - a aliança contra a qual EUA, Grã-Bretanha e seus aliados lutaram na Segunda Guerra Mundial - haviam se tornado democracias ativas e aliados importantes dos EUA e da Europa na construção e na manutenção da ordem internacional enquanto, por outro lado, a posição internacional da URSS e da China também havia mudado ao longo da segunda metade do século XX. O desparecimento do bloco socialista e o colapso da URSS trouxeram um novo papel para a Rússia na ordem internacional enquanto a China que agora se fazia representar na ONU, não era mais a China de Chiang Kai-Shek, aliada do Ocidente, mas a República Popular da China, criada pela revolução comunista de Mao TséTung. Assim, eram muitos os fatos que justificavam o entendimento de que a composição do Conselho de Segurança não mais refletia a ordem vigente no cenário mundial e, em consequência, acreditava-se que uma reforma da ONU seria necessária para torná-la mais representativa da ordem mundial. O fato é que na política internacional a concretização de reformas das instituições sempre se revelou um passo muito mais difícil do que a criação de uma nova entidade, como havia ocorrido com a própria ONU que, apesar de ser bastante semelhante à Liga das Nações em termos de objetivos e até de procedimentos, ao final da Segunda Guerra Mundial preferiu-se criar a nova entidade e, em seguida, transferir o patrimônio material e político da Liga das Nações para a ONU.

A segunda ordem de argumentos para a diplomacia brasileira investir na obtenção de um assento permanente no Conselho de Segurança da ONU era o entendimento de que, politicamente, o Brasil era um "candidato natural" dos países em desenvolvimento e, geograficamente, um representante também

\footnotetext{
${ }^{9}$ Em 1950 o PNB dos EUA era maior do que a soma das demais grandes potencias (Reino
} Unido, França, Alemanha, Itália, Japão e URSS). 
natural dos países latino-americanos, por suas dimensões e por seu peso político internacional que se refletia, por exemplo, no papel que desempenhara na criação, juntamente com outros países em desenvolvimento, do G-20, que podia servir de contraponto ao grupo dos 8 países mais ricos do mundo (G$7+1) \cdot \cdot^{10}$

Um outro argumento da diplomacia brasileira era o de que sua participação no Conselho de Segurança da ONU seria vista pelas potências como um reforço para os objetivos centrais da ONU, que eram o de promover a paz e o entendimento pacífico entre as nações. $\mathrm{O}$ argumento considerava que a longa tradição diplomática brasileira seria uma forte credencial para qualificar o país para um assento permanente no Conselho de Segurança da ONU. Essa tradição apontava para uma história do país predominantemente pacífica em relação à convivência com seus vizinhos e apontava também para a índole e a competência da diplomacia brasileira, marcada pela preferência permanente pela solução pacífica das controvérsias e pela ênfase e no desenvolvimento da capacidade de negociação. É curioso notar que esses argumentos eram bastante semelhantes aos que haviam sido utilizados na década de 1920, quando a diplomacia brasileira se empenhara em obter um assento permanente do Conselho da Liga das Nações.

É notável que no início do século XXI os governantes e responsáveis pela política exterior não prestassem atenção à experiência vivida oito décadas antes quando, de um lado, as grandes potências se revelaram muito mais preocupadas com seus interesses individuais e com o jogo de poder na política internacional, enquanto de outro lado, as nações periféricas, sobretudo nas vizinhanças do Brasil, observavam a demanda brasileira por um assento permanente no Conselho da Liga das Nações como uma inciativa para reforçar a posição brasileira diante delas e não como uma força emergente para, eventualmente, defendê-las contra políticas de poder das grandes potências. ${ }^{11}$

\footnotetext{
${ }^{10}$ Neste caso trata-se do G-20 dos países em desenvolvimento criado em Cancún (México) em 2003, na esteira da conferência da OMC e não do G-20, criado em 1999, reunindo as 19 maiores economias do mundo e mais a União Europeia, cujo propósito mais imediato era o de discutir e encaminhar soluções para os problemas financeiros globais.

${ }^{11}$ No capítulo 3 do livro O Brasil na Liga das Nações (op. cit.) Eugênio VARGAS discute as várias iniciativas tomadas pelo governo Arthur Bernardes entre 1922 e 1925 no sentido de qualificar a demanda brasileira por um assento permanente no Conselho da Liga. O livro relata também a
} 
No curto prazo, talvez o efeito mais importante da orientação da política exterior do Brasil no sentido de obter um assento permanente no Conselho de Segurança da ONU tenha sido a de comprometer o MERCOSUl e o projeto de integração regional. Tal como ocorrera na época da Liga das Nações, os países vizinhos no continente sul-americano jamais viram o Brasil como "representante", mas sim como rival nessas instâncias multilaterais, especialmente em relação à demanda por um assento permanente no Conselho de Segurança da ONU. Vale notar que essa demanda tinha pouco respaldo até mesmo junto à população brasileira. Com efeito, um trabalho de pesquisa realizado por Amaury de Souza na época em que a demanda brasileira por um assento permanente no Conselho de Segurança da ONU estava no auge, revelava esse descompasso entre a diplomacia e a opinião pública. Amaury de Souza consultou a opinião de profissionais de várias categorias, entre os quais executivos empresariais, professores, jornalistas e integrantes das áreas técnicas do Legislativo e do Executivo a respeito da política externa do governo Lula e os resultados revelaram que, entre 18 prioridades sugeridas pela pesquisa, a demanda por um assento permanente no Conselho de Segurança da ONU tinha muito pouca aprovação, ficando em $16^{\circ}$. lugar, superando apenas "controlar e reduə̧ir a imigração ilegal para o País" (13\%) e "fortalecer a CPLP Comunidade de Paises de Lingua Portuguesa" (12\%) (SOUZA, 2009).

Como já mencionado, a vertente "globalista" do pensamento em política exterior considerava que havia um jogo mundial do poder e que o Brasil deveria atuar ativamente nesse jogo. Esse pensamento coincidia com a eleição em outros países da região de governos de esquerda dentro do espectro político, para quem os EUA eram um dos grandes obstáculos a serem contornados. Cabe notar que o termo "globalismo" é bastante vago e controvertido. Na presente análise o termo é entendido como uma alternativa à expressão "globalização", uma espécie de versão conceitual do que ocorrera em 2001, quando foi criado o Fórum Social Mundial como alternativa ao Fórum Econômico Mundial de Davos. O destino dessa visão do globalismo parece ter sido o mesmo do Fórum Social Mundial, que perdeu completamente o interesse enquanto, por outro lado, o Fórum de Davos continuou muito 
ativo como uma instância efetiva de debates para autoridades políticas e empresariais das nações mais influentes do mundo, que podiam expor suas preocupações e ouvir propostas em estágio preliminar para as grandes questões da economia mundial.

\section{Política e economia no Brasil depois da redemocratização}

A projeção de qualquer país no cenário internacional tanto no âmbito regional quanto no cenário global depende fundamentalmente do desempenho da nação. As dimensões geográfica e demográfica podem ser condições necessárias da posição internacional do país, mas estão longe de ser suficientes. A China, apesar de suas dimensões continentais, só se tornou uma nação realmente relevante na cena internacional após o longo período de crescimento iniciado com Deng Xiaoping na década de 1980. Até então, a China não passava de um uma nação fechada, com todos os indicadores do 'subdesenvolvimento", sem qualquer expressão internacional, na realidade, uma verdadeira incógnita para a política internacional. Por outro lado, uma economia como a da Suíça, reconhecidamente estável e confiável de longa data, capaz até mesmo de transpor sem abalos as grandes crises do século XX, jamais teve sua moeda sequer cogitada para desempenhar papel de relevância no sistema monetário internacional em virtude das limitadas dimensões de sua economia. Além desses, existem muitos outros casos que ilustram essa relação entre as dimensões de uma nação, seu desempenho econômico e político e sua relevância no cenário da política e da economia mundial.

Nas últimas décadas, efetivamente o Brasil teve algum papel de relevância no cenário internacional apenas em uns poucos momentos. Em larga medida, na maior parte do tempo seu desempenho econômico e político tem ficado muito aquém de suas dimensões geográficas e demográficas e de seu potencial econômico. Os governos militares ensaiaram um processo de aglutinação dos recursos e das energias sociais e econômicas em torno de um projeto de âmbito nacional nesse sentido, mas o projeto que ficou conhecido como "Brasil Potência" apresentava muitos problemas e foi alvo de muitas críticas que, em geral, principiavam com a crise de um regime autoritário que perdia sustentação política rapidamente reduzindo muito o espaço para enfrentar quaisquer dificuldades que eventualmente emergissem. Nesse quadro, 
as turbulências e as pressões geradas pela crise do petróleo da década de 1970 foram fatais para a estabilidade do regime político bem como para as estratégias de desenvolvimento. $\mathrm{Na}$ realidade, a crise do petróleo era apenas a parte mais visível e ruidosa das grandes mudanças em curso na ordem econômica internacional, entre as quais destacava-se a substancial redução das tradicionais fontes oficiais de financiamento, notadamente governos, Banco Mundial e as várias agências oficiais de fomento ao desenvolvimento internacional.

A substituição do regime autoritário por uma ordem democrática, apesar do grande entusiasmo - ou talvez em razão do grande entusiasmo - foi realizada de forma que alguns problemas de governabilidade e de eficiência iriam emergir na ordem econômica e política nas décadas seguintes. É certo que as virtudes da democracia são indiscutíveis. A história mostra que os regimes democráticos são aqueles que, como nenhum outro, têm garantido valores essenciais como a liberdade e a dignidade do cidadão. Apesar de tudo, "democracia" é apenas um conceito abstrato. No mundo real o termo só existe no plural. No mundo real o que existe é a "democracia inglesa", a "democracia americana", a "democracia francesa", a "democracia holandesa", entre outras. O que é comum nessas "democracias" é que, além de garantir valores essenciais como a liberdade, essas democracias procuram adaptar-se suas instituições políticas às tradições e às peculiaridades culturais nacionais e, ao mesmo tempo, procura organizar e regular a ordem social e econômica de forma que ajudem a promover o progresso e a prosperidade da nação. $\mathrm{O}$ desejo de prosperidade está presente não apenas nas chamadas sociedades ocidentais, mas na grande maioria das sociedades espalhadas pelos cinco continentes. Nesse ambiente marcado pela diversidade, a qualidade do regime pode variar de lugar para lugar e também ao longo do tempo significando que o fato de haver democracia não significa que haverá progresso e prosperidade. Os surveys periodicamente produzidos por organizações internacionais como o Banco Mundial e a Organização para Cooperação Econômica e o Desenvolvimento apontam essas diferenças de desempenho, ou seja, há sociedades democráticas que inovam e prosperam mais do que outras. Esse aspecto revela-se especialmente importante para as economias em desenvolvimento como o Brasil para quem prosperar significa corrigir 
desigualdades sociais e qualificar-se para levar para considerável parte da população os benefícios das modernas tecnologias.

Com o retorno da democracia, desde 1989 o Brasil tem realizado ininterruptamente eleições livres e o estado de direito passou a regular a vida dos indivíduos e das organizações públicas e privadas. Com efeito, o voto livre - um dos quesitos essenciais dos regimes democráticos - tem sido praticado em todos os rincões deste Brasil de dimensões continentais. Na realidade, a tradição de democracia no Brasil não remonta apenas ao estabelecimento da República há exatamente um século antes da redemocratização. Mesmo nos tempos do Império, a democracia era uma prática vivenciada notavelmente até pelo próprio Imperador Pedro II na forma de uma monarquia constitucional. Apesar de tudo, o estado de direito e o funcionamento livre e regular das instituições democráticas, embora importantes, são apenas parte da história.

Com efeito, de uma forma geral, a história recente mostra que os sucessivos governos brasileiros, embora democraticamente constituídos, têm negligenciado o fato de que o sucesso econômico constitui fator essencial tanto para a melhoria das condições sociais internas quanto para a própria ordem internacional. Uma nação pobre não contribui em nada para a comunidade internacional, na realidade torna-se um peso e uma fonte de problemas para seus vizinhos e para a comunidade internacional como um todo. Uma visão de conjunto da posição brasileira no cenário internacional revela que a incapacidade de buscar o progresso, associada a algumas escolhas equivocadas têm produzido a estagnação dessa posição internacional. Por vezes, ao invés de preocupar-se com posturas e alianças de inspiração mais ideológica e de sonhos de poder, a nação deveria estar mais adequadamente preparada tanto para enfrentar com sucesso os problemas que surgem de tempos em tempos na esfera internacional quanto para captar positivamente as oportunidades que também emergem na política e nas relações econômicas internacionais. Objetivamente, a nação precisa tanto de instituições que proporcionem segurança jurídica e estabilidade política - ou seja, obter a confiança internacional - quanto de uma economia suficientemente robusta e saudável capaz de assegurar que o país fique ao menos razoavelmente alinhado com os padrões mundiais. As tabelas a seguir mostram que o crescimento da economia 
brasileira tem ficado bem abaixo da média mundial, ou seja, tem se empobrecido em termos relativos. As tabelas mostram também que há pelo menos duas décadas as taxas de investimento têm ficado substantivamente abaixo das taxas praticadas por outros países. Essas taxas de investimento são importantes porque refletem a parcela do PIB que o país destina não apenas à inovação tecnológica e ao aumento da produtividade e da capacidade de produção de bens e de serviços, mas refletem também os investimentos feitos em educação, nos serviços de assistência médica e em outros serviços sociais, assim como na ampliação e manutenção da infraestrutura de esgotos, saneamento, comunicações e em todos os modais de transporte, ou seja, portos, aeroportos, estradas, ferrovias e transporte urbano. Um país como a China, que vem apresentando taxas elevadas e consistentes de crescimento econômico investe, proporcionalmente, mais do que o dobro do Brasil e até mesmo países "prontos" como a França, que têm toda a infraestrutura social e econômica madura, investe significativamente mais do que o Brasil, como mostra a tabela 2. O fato é que esses investimentos são cumulativos e cada ano com baixos investimentos significa instalações industriais deterioradas ou não construídas, rodovias que deixaram de ajudar a dinamizar a economia, alguns milhares de jovens que não terão boas escolas ou cidades que continuarão com boa parte da população sem acesso aos benefícios da água encanada e dos esgotos tratados, além e muitos outros elementos de infraestrutura econômica e social deteriorados dificultando o bem estar do cidadão em suas rotinas diárias e também fomentando a criminalidade em todas as suas formas. Em valores, de acordo com a tabela 2, significa que o Brasil (setor público + setor privado) deixou de investir algo em torno de US\$ 100 bilhões por ano ao longo de duas décadas. ${ }^{12}$

${ }^{12}$ Em valores de Dezembro/2019. 
Tabela 1 - CRESCIMENTO ECONÔMICO, PAÍSES SELECIONADOS

ANOS RECENTES $2007-2018(\%)$

\begin{tabular}{ccccccccc}
\hline País / região & $\mathbf{2 0 0 7}$ & $\mathbf{2 0 1 0}$ & $\mathbf{2 0 1 3}$ & $\mathbf{2 0 1 4}$ & $\mathbf{2 0 1 5}$ & $\mathbf{2 0 1 6}$ & $\mathbf{2 0 1 8}$ & $\begin{array}{c}\mathbf{2 0 1 3 - 2 0 1 8} \\
\text { (média } \\
\text { anual) }\end{array}$ \\
\hline Brasil & 6,07 & 7,52 & 3,00 & 0,50 & $-3,54$ & $-3,27$ & 1,31 & $-0,40$ \\
Argentina & 9,00 & 10,12 & 2,40 & $-2,51$ & 2,73 & $-2,08$ & $-2,48$ & 0,38 \\
Chile & 4,90 & 5,84 & 4,04 & 1,76 & 2,30 & 1,67 & 4,02 & 2,75 \\
Colômbia & 6,84 & 4,34 & 4,56 & 4,72 & 2,95 & 2,08 & 2,56 & 3,37 \\
México & 2,29 & 5,11 & 1,35 & 2,80 & 3,28 & 2,91 & 2,13 & 2,49 \\
Peru & 8,51 & 8,33 & 5,85 & 2,38 & 3,25 & 3,95 & 3,97 & 3,88 \\
A. Latina e Caribe & 5,51 & 5,84 & 2,75 & 1,00 & 0,08 & $-0,33$ & 1,57 & 1,01 \\
China & 14,23 & 10,63 & 7,76 & 7,30 & 6,90 & 6,73 & 6,56 & 7,05 \\
Mundo & 4,31 & 4,29 & 2,65 & 2,83 & 2,85 & 2,58 & 3,05 & 2,79 \\
\hline
\end{tabular}

Fonte: World Bank.

Tabela 2 - INVESTIMENTO BRUTO DO PAÍS COMO PROPORÇÃO DO PIB

\begin{tabular}{cccccc}
\hline Ano & Brasil & Mundo & China & França & Chile \\
\hline 2000 & 16,8 & 24,3 & 34,4 & 22,5 & 22,1 \\
2002 & 16,4 & 23,2 & 37,0 & 21,3 & 22,3 \\
2004 & 16,1 & 24,5 & 42,8 & 21,9 & 19,8 \\
2006 & 16,4 & 25,3 & 40,9 & 23,2 & 20,8 \\
2008 & 19,1 & 25,5 & 43,2 & 24,1 & 23,5 \\
2010 & 19,5 & 24,2 & 47,6 & 21,9 & 26,8 \\
2012 & 18,1 & 24,3 & 47,2 & 22,6 & 23,1 \\
2016 & 16,4 & 23,8 & 44,2 & 22,7 & 26,5 \\
\hline
\end{tabular}

Fonte: OCDE. National Accounts Data Files

Em resumo, a trajetória recente da política exterior do Brasil tem apresentado poucos resultados, em grande parte por estar desconectada das bases econômicas, sociais e políticas da nação. O Brasil pode ter um grande potencial de soft power, mas para realizar esse potencial será preciso que a nação inspire confiança na comunidade internacional em todos os sentidos, a começar por uma taxa de crescimento econômico ao menos mais elevada do que a média mundial. Escolher opções como integração econômica regional, até pelas dimensões do país, o que se espera é que o país contribua para que esse arranjo floresça e não seja um verdadeiro "peso morto" nesse empreendimento, isto é, que se torne um fator de estímulo e de canalização positiva das energias para todos os demais parceiros. $\mathrm{Na}$ realidade, a condição 
necessária (embora não suficiente) para que um arranjo como o MERCOSUL avançasse efetivamente é que o integrante de maior peso (no caso o Brasil) apresentasse esse desempenho positivo, consistente e construtivo.

\section{Brasil um país do futuro, até quando?}

Desde que Stefan Zweig publicou em 1941 seu livro "Brasil, um País do Futuro", cada geração experimentou a sensação de que haveria de ver esse futuro chegar pensando em um Brasil próspero e poderoso no concerto das nações (ZWEIG, 2013). ${ }^{13} \mathrm{Na}$ realidade, o sentido que Zweig dava a esse futuro não era esse. Sua experiência de vida era o de sua terra natal, a Áustria, e do continente europeu, que vivenciaram ao longo da primeira metade do século XX o sofrimento e a destruição das duas guerras mundiais e a perseguição implacável aos judeus pelo nazismo - uma perseguição que afinal trouxera Zweig para o Brasil em 1940. Para Stefan Zweig, o futuro promissor que antevia para o Brasil era o de um país pacífico e isento dessas loucuras coletivas que marcaram seu país e a Europa de seu tempo. Na introdução do livro escreve Zweig: "Por isso, é sobre a existência do Brasil, cujo único desejo é a construção pacifica, que repousam nossas maiores esperanças de uma civilizaçãa futura e de pacificação do nosso mundo devastado pelo ódio e pela loucura ... É por isso que escrevi este livro".

Apesar de tudo, é parte da natureza humana a permanente busca pelo progresso e pela prosperidade individual e coletiva e, nesse quesito, as esperanças da nação brasileira têm sido sistematicamente frustradas, geração após geração, por muitas razões que, neste ensaio, não cabe discutir (MOURA, 2017) ${ }^{14}$ Um ponto que parece oportuno analisar nestas considerações que devem servir de conclusão sobre as perspectivas para a política exterior do país é o fato de que, aparentemente, os sucessivos governantes e as forças políticas no país não têm levado na devida conta o fato de que, na essência, progresso e prosperidade são a base sobre a qual se assentam a posição de uma nação no cenário internacional. $\mathrm{Na}$ realidade, a política exterior de qualquer país depende essencialmente de duas ordens de variáveis: de um lado, as variáveis que

\footnotetext{
13 A primeira edição de 1941 de Brasil um País do Futuro, foi lançada simultaneamente em alemão, inglês, sueco e francês, além do português.

${ }^{14}$ Em seu livro Sérgio Moura (2017) Podemos ser Prósperos. Se os Políticos Deixarem discute essa questão de forma bastante exaustiva e interessante, lembrando o Brasil, o País dos Coitadinhos, de Emil FARHAT (1966), de grande sucesso na época.
} 
conformam o meio internacional, sobre as quais até mesmo grandes potências têm pouca influência; de outro lado, as capacidades nacionais em termos de recursos econômicos sobre as quais se assentam tanto o hard power quanto o soft power. $\mathrm{Na}$ essência, orquestrar essas capacidades constitui uma das missões essenciais e intransferíveis dos governos.

Nestas reflexões conclusivas, portanto, cabe apontar o fato de que, vitualmente, os sucessivos governos no Brasil têm buscado alternativas de política exterior como integração regional, investimento em instâncias multilaterais, ou em tópicos como alianças com grandes potências ou com nações em desenvolvimento, mas têm descuidado da construção de uma base social e econômica nacional que, efetivamente, são capazes de tornar o país um ator capaz de se beneficiar dos fluxos internacionais de comércio e de capital e também de exercer alguma influência positiva na ordem internacional. Com efeito, o meio internacional continua a ser eminentemente anárquico no sentido de que as nações podem construir, modificar ou mesmo eliminar regimes, mas a história tem mostrado que qualquer dessas possibilidades, ocorrem a posteriori, isto é, os desenvolvimentos ocorrem e, em seguida, procura-se estabelecer algum referencial normativo para esses desenvolvimentos. Mesmo em casos como o da integração europeia as instituições foram criadas para ordenar e dar segurança à integração comercial, social e política que, de muitas maneiras, já existiam há séculos na Europa.

Em termos gerais, o caso do desenvolvimento tecnológico é bastante ilustrativo da dimensão anárquica do meio internacional. De muitas formas a tecnologia desempenha um papel central nas relações interacionais da atualidade uma vez que influencia diretamente os padrões de produtividade e a capacidade das nações transformar seus recursos naturais e humanos em riqueza. Por exemplo, os desenvolvimentos ocorridos no mundo das tecnologias de informação, processamento e transmissão de dados e de imagens, abriram um novo mundo de oportunidades para os negócios em toda parte e não apenas em tradicionais centros dinâmicos da economia mundial. A globalização financeira e comercial só foi possível por meio de tecnologias como essas, que permitiram a integração internacional da produção industrial assim como dos mercados financeiros ajudando, dessa forma, a promover uma 
verdadeira redistribuição mundial da atividade econômica e da riqueza (ZAKARIA, 2008). ${ }^{15}$ No caso recente mais notável, a ascensão da China ao status de segunda maior potência mundial, deu-se por meio do enorme fluxo de capitais e de tecnologia oriundos dos EUA, do Japão e da Europa. Um processo que foi motivado não pela disposição deliberada desses centros de poder e de riqueza mundial no sentido de fortalecer a economia chinesa, mas em decorrência dessa característica intrínseca do meio internacional que os analistas chamam de "condição anárquica", isto é, sem uma autoridade central e um ordenamento formalmente estabelecido, e onde cabe a cada ator escolher a forma e as estratégias de se relacionar com as forças em ação no meio internacional para obter benefícios ou, por vezes, simplesmente para contornar problemas. Nesse sentido, de uma forma geral, a história recente mostra que os sucessivos governos brasileiros têm negligenciado esses fatos. Objetivamente, pode-se afirmar que uma nação como o Brasil precisa tanto de democracia quanto de instituições robustas que proporcionem segurança jurídica e estabilidade política em condições de contar com a confiança internacional para ser um participante ativo e capaz de, em condições de razoável igualdade, compartilhar da grande aventura da ordem internacional na busca do progresso espiritual e material.

Em resumo, a trajetória recente da política exterior do Brasil tem apresentado poucos resultados, em grande parte por estar desconectada das bases econômicas, sociais e políticas da nação. O Brasil pode ter um grande potencial de soft power, mas para realizar esse potencial será preciso que a nação inspire confiança na comunidade internacional em todos os sentidos, a começar por uma taxa de crescimento econômico mais elevada do que a média mundial para indicar claramente que a nação está efetivamente reduzindo sua pobreza relativa e melhorando consistentemente seus indicadores sociais. Uma análise mais acurada mostraria que, em larga medida, o BRICS só existe em razão da China e do que ela representa, especialmente em termos simbólicos

15 Em O Mundo Pós-Americano, Fareed ZAKaria faz um balanço de longo prazo da ordem mundial, desde que se tornou visível no século XVI. O autor chama de "movimentos tectônicos" as transformações que levaram ao centro dessa ordem primeiro a Europa, depois os EUA e finalmente o que ele chama de "ascensão do resto" num processo movido muito menos por guerras do que pelo gênio humano e pela criatividade que incrementa a produção e a produtividade. 
como nação, cuja relevância no mundo em termos econômicos, tornou-se indiscutível e cujo desempenho ao longo de três décadas tornou-se uma verdadeira inspiração para substancial parte das nações do mundo.

Ella Wilcox, escritora e poetisa norte-americana fez sucesso em seu tempo, mas tornou-se conhecida universalmente por uma frase que se transformou em adágio popular em muitos lugares: "Ria e o mundo rirá com você. Chore e você chorará sozinho". ${ }^{16}$ Rubens Ricúpero ainda no início da década de 1990, de certa forma, deu a esse fato uma interpretação teórica argumentando que nas relações entre os países da América Latina predominavam as relações triangulares, isto é, não se podia entender as relações entre os países da região a não ser por meio de triângulos onde sempre há um vértice ocupado pelos EUA ou, em tempos mais recentes, por outra potência de sucesso de fora da região (RiCÚPERO, 1996). A verdade é que países de sucesso, que inspiram e transmitem confiança, não precisam buscar parceiros - têm o privilégio de os escolher. Mesmo na esfera do comportamento humano pode-se dizer que o sucesso atrai enquanto o fracasso afasta ou nos torna indiferentes. Nos últimos anos as agências de classificação de risco financeiro tornaram-se populares na literatura de relações internacionais. Apesar de tudo, pouca gente tem prestado a devida atenção para o fato de que os grandes fluxos migratórios de pessoas, mesmo aqueles causados por motivações dramáticas e trágicas, instintivamente, tendem a seguir as mesmas direções recomendadas pela Standard \& Poors e por outras agências de classificação de risco financeiro, isto é, a preferência dos migrantes é, notavelmente, pelos países “Triple A”. De fato, nestes tempos, um dos indicadores mais expressivos do desempenho econômico e social de um país é o movimento migratório. Segundo notícias recentes divulgadas pelo Ministério das Relações Exteriores, o número de brasileiros vivendo no exterior é de cerca de 3 milhões de pessoas, enquanto o número de estrangeiros vivendo no Brasil não chega a 750 mil, ou seja, é 4 vezes menor. Vale notar que esse número de estrangeiros vivendo atualmente no Brasil é menor do que o de estrangeiros vivendo em países próximos como a Argentina

\footnotetext{
${ }^{16}$ Rejoice, and men will seek you; Grieve, and they turn and go;

(...)

Be glad, and your friends are many;

Be sad, and you lose them all.
} 
e o Paraguai. Certamente que um tal quadro não poderá ser revertido apenas pela política exterior, será preciso que o próprio Estado brasileiro reveja suas prioridades e o funcionamento de suas instituições. Não basta ser uma democracia, é preciso ser uma democracia eficiente, capaz de atender os desejos mais profundos e mais elevados da nação, os quais, na maioria das vezes, não são expressos em manifestações ruidosas.

\section{Referências}

Batista Jr, P. N. A Moratória de 1987. Folha de S. Paulo, 20/Fev./1997.

Cervo, A. L.; Bueno, C. História da Politica Exterior do Brasil de (Editora UnB, $4^{\mathrm{a}}$. Edição, 2011.

Farhat, E. Brasil, o País dos Coitadinhos. Cia. Editora Nacional, 1966.

Jaguaribe, H. Significação de Mercosul. In Mercosul, Sinopse Estatística. Vol. I, IBGE, Rio de Janeiro, 1992.

Kennedy, P. The Rise and Fall of the Great Powers. London: Fontana Press, 1988.

Moura, S. Podemos ser Prósperos. Se os Políticos Deixarem. R. Janeiro, 2017.

Oliveira, E.; Duchiade, A. O Globo, 5/Junho/2019.

Pearson Commission on International Development, Partners in Development, The World Bank, Washington, D.C., 1969.

Ricúpero, R. O Brasil, a América Latina e os EUA desde 1930: 60 Anos de uma Relação Triangular. Pub. em J. G. Albuquerque (Org.) 60 Anos de Política Externa Brasileira (1930-1990). NUPRI/USP, 1996. Vol. 2 pp. 37-60.

SouzA, A. de. A Agenda Internacional do Brasil: a Politica Externa Brasileira de FHC a Lula. Rio de Janeiro: Editora Campus/Elsevier, 2009.

VARGAS, E. O Brasil na Liga das Nacões. 1919-1926. Editora Funag/Editora UFRGS, 2000.

Wilcox, E. W. Solitude, The Sun, May, 1883

Zakaria, F. O Mundo Pós-Americano. São Paulo: Companhia das Letras, 2008.

ZWEIG, S. Brasil. Um País do Futuro. Porto Alegre: L\&PM Editores, 2013. 